\title{
Article
}

\section{Modification of PLA Scaffold Surface for Medical Applications}

\author{
Michał Młotek *, Agnieszka Gadomska-Gajadhur (D), Aleksandra Sobczak, Aleksandra Kruk, Michalina Perron \\ and Krzysztof Krawczyk
}

check for updates

Citation: Młotek, M.;

Gadomska-Gajadhur, A.; Sobczak, A.; Kruk, A.; Perron, M.; Krawczyk, K. Modification of PLA Scaffold Surface for Medical Applications. Appl. Sci. 2021, 11, 1815. https://doi.org/ 10.3390/app11041815

Academic Editor: Rossella Bedin

Received: 18 January 2021

Accepted: 12 February 2021

Published: 18 February 2021

Publisher's Note: MDPI stays neutral with regard to jurisdictional claims in published maps and institutional affiliations.

Copyright: (c) 2021 by the authors. Licensee MDPI, Basel, Switzerland. This article is an open access article distributed under the terms and conditions of the Creative Commons Attribution (CC BY) license (https:/ / creativecommons.org/licenses/by/ $4.0 /)$.
Faculty of Chemistry, Warsaw University of Technology, 0-664 Warszawa, Poland; agadomska@ch.pw.edu.pl (A.G.-G.); ola.sobczak@o2.pl (A.S.); aleksandrakruk100@gmail.com (A.K.); michalina.perron@gmail.com (M.P.); kraw@ch.pw.edu.pl (K.K.)

* Correspondence: mmlotek@ch.pw.edu.pl

\begin{abstract}
Materials used for medical applications (e.g., the cellular scaffold) should have not only the specific chemical composition, but the surface layer properties as well. For this reason, a method which enables an increase in the number of pores, wettability of the surface, and improvement the conditions of nutrient transportation into the membrane is being studied. The plasma of a dielectric barrier discharge was applied for the surface modification of polylactide obtained by dry or wet phase inversion. The plasma-modified surface was analyzed by contact angle measurements with water and diiodomethane. The surface free energy (SFE) was calculated by the Owens-Wendt method. The highest SFE and its polar component $\left(67.6 \mathrm{~mJ} / \mathrm{m}^{2}\right.$ and $39.5 \mathrm{~mJ} / \mathrm{m}^{2}$, respectively) were received when the process was conducted in an $\mathrm{Ar}+\mathrm{CO}_{2}$ gas mixture with a discharge power of $20 \mathrm{~W}$. The purpose of this research was to increase the wettability and porosity of the membrane's surface. It can be concluded that the dielectric barrier discharge can effectively change the surface of the polylactide membranes, and that the structure of the modified membranes was not damaged during modification. The process of modification was easier for the membranes made by dry phase inversion. These materials had higher SFE values after the modification.
\end{abstract}

Keywords: polylactide; scaffold; dielectric barrier discharge plasma; plasma modification

\section{Introduction}

The use of a biomaterial which allows cells to grow on it creates the possibility of preparation of adequate tissue in laboratory conditions in the future. The tissue grown on biomaterial will be able to replace damaged parts of the human body. Cellular scaffolds should be the mechanical support for cells and tissues. Scaffold ought to merge multiplying cells, regulate their progression and diversification, and affect their size and shape. Polymeric membrane surfaces are characterized by a small number of poorly connected pores, so it is hard for tissues to penetrate them. Moreover, it makes the transport of nutrients and metabolites difficult [1]. For this reason, a method which allows the increase of the number of pores, wettability of the surface, and improvement of the conditions of nutrient transportation into the membrane is being studied. The main direction of this research is to develop methods for the surface modification of polymeric materials that will enable the increase of their surface roughness, adhesive strength, wettability, and number of built-in functional groups.

Chemical and physical methods are used to modify the surface of polymeric materials. The chemical methods mainly consist of immersion of the modified material in highly oxidizing liquids [2]. The main disadvantages of such techniques are the corrosive impact of the used liquids, high consumption of water used during flushing of the modified material, significant environmental contamination with aggressive chemicals, low productivity of the modification processes, and high process costs.

There are many physical methods [3,4]. One of them is modification with lowtemperature plasma. The advantages of plasma processes are the relatively low operating costs and simple construction of the reactors used for modification. 
Polymer materials used in tissue engineering can be divided into natural and synthetic types [5]. The most commonly used polymer materials are easily processed and bioresorb to nontoxic substances, such as carbon dioxide and water. Among the large group of biomaterials used to produce three-dimensional scaffold biodegradable polymers, polylactide (PLA), polyglycolide (PGA), polylactide-glycolide (PLGA) copolymer, and polycaprolactone (PCL) deserve special attention [6-8].

Polylactide is a frequently used biodegradable polymer. It is thermoplastic, has good mechanical properties, and is completely biodegradable and biocompatible. PLA is obtained from lactic acid by two methods: ring-opening polymerization and direct polycondensation [9]. In recent years, one of the methods of plastic modification used in material engineering and medicine has been plasma electric discharge [10-20]. The main purpose of modifying the surface layer of polymeric materials is to improve the wettability and adhesive properties.

The use of plasma modification is an effective and economical surface treatment technique for many polymer materials. The advantage of this method is the ability to induce a selective change of the surface properties. The use of various gases such as argon, oxygen, nitrogen, fluorine, carbon dioxide, or water vapor allows the creation of unique surface properties, depending on the type of polymer used. The use of oxygen plasma can increase the surface energy of polymers, while the action of plasma generated in fluorine can reduce the surface energy and improve the chemical resistance. By using plasma generated in an inert gas, the polymer surface can be crosslinked [21].

The use of plasma jet discharge has also reduced the hydrophobicity of polymeric materials. Polypropylene (PP-H), acrylonitrile butadiene styrene (ABS), and high impact polystyrene (HIPS) polymers were treated in a plasma jet reactor in helium and air. There was no effect by an increase of the gas flow rate and the concentration of air in the gas on the change of the contact angle. The plasma exposure time on the sample's surface was $30 \mathrm{~s}$ [12].

The types of discharge most commonly used on an industrial scale to produce lowtemperature plasma at atmospheric pressure and room temperature are a corona discharge or a dielectric barrier discharge (DBD) [22-24]. A DBD is often applied in the modification of surfaces because it can be used in a wide range of pressures, gases, and discharge powers with a limited value of energy, which reduces the possibility of damaging materials during modification. The aim of this work was to investigate the effect of the low-temperature plasma of a DBD on the changes occurring on the surface and in the inner structure of membranes for medical applications. The change of these parameters was intended to increase the wettability of the scaffold's surface. The finished scaffold modification, plasma source, and gas composition in which it was generated are the novelties of the study. The influence of the exposure time, type of gas, and discharge power on the surface properties were tested. The effect of DBD plasma on the membrane's surface was determined by the changes of the surface free energy (SFE), as well as the polar and dispersion components.

\section{Experimental}

\subsection{Plasma Source}

PLA membranes were modified in DBD plasma in the following $\mathrm{CO}_{2}$ and $\mathrm{Ar}$ mixtures: $50 \%_{\text {vol. }}$ Ar $+50 \%_{\text {vol. }}$ air or $50 \%_{\text {vol. }}$ Ar $+50 \%_{\text {vol. }} \mathrm{CO}_{2}$. Multax $5 \mathrm{~N}$ gases were used to conduct the process. The gas composition was regulated by Bronkhorst mass flow controllers (Figure 1). The gas was introduced by the inlet in the high-voltage electrode and had to flow through the sample and porous electrode to leave the reactor. The gas flow rate in all the experiments was $20 \mathrm{Nl} / \mathrm{h}$, the discharge power was in the range $15-50 \mathrm{~W}$, and the exposure time was 15,30 , or $60 \mathrm{~s}$. The effect of the DBD plasma and process parameters on the PLA membrane's surface was investigated. 


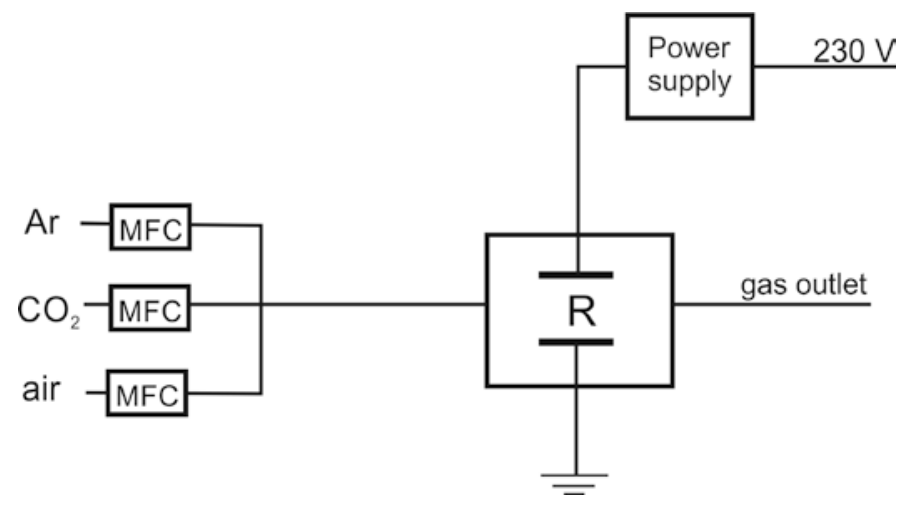

Figure 1. The scheme of the system for polylactide (PLA) membrane modification.

The reactor had a porous, metal grounded electrode, on which a modified membrane was placed. The dielectric was located on the high-voltage electrode. The discharge gap was $3 \mathrm{~mm}$ wide (Figure 2). The reactor was supplied with a multipulse alternating current of $30 \mathrm{kHz}$ for $4 \mathrm{~ms}$ with an $8 \mathrm{~ms}$ interval. The average discharge power varied in the range of $10-50 \mathrm{~W}$.

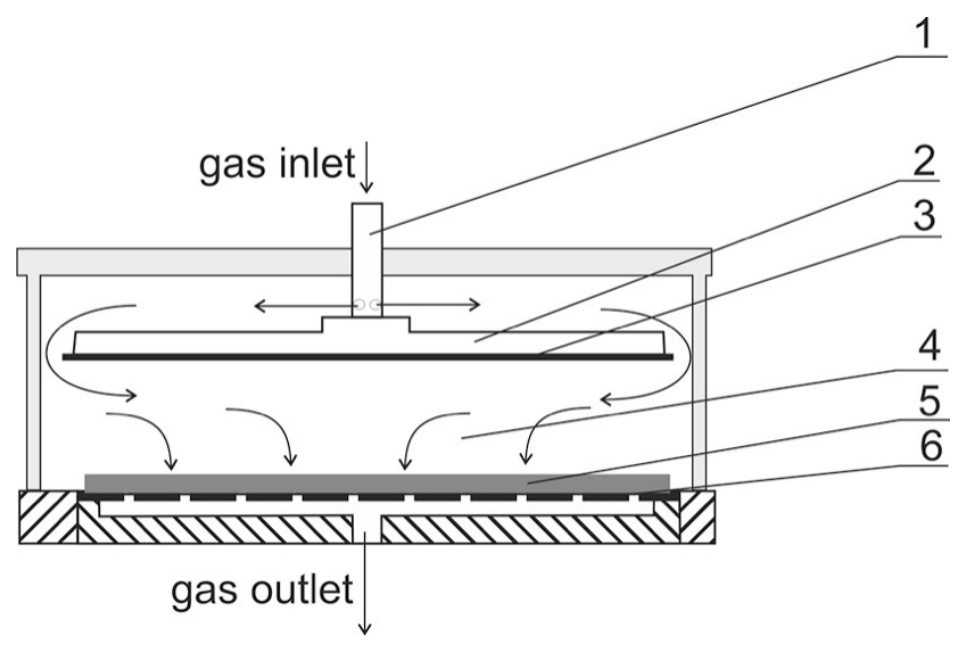

Figure 2. The scheme of the reactor. The arrows indicate the direction of the gas flow. $1=$ gas inlet, 2 = high-voltage electrode, 3 = dielectric barrier, 4 = discharge gap, 5 = modified sample, and $6=$ grounded electrode [25].

\subsection{Analytical Equipment}

The surface of the modified scaffold was tested by measuring the contact angle with a microQ FMA037 industrial digital camera. Water and diiodomethane were used as measuring liquids. The polar component $(\mathrm{pm})$, dispersion component $(\mathrm{dm})$, and surface free energy (SFE) were calculated by the Owens-Wendt method. The analyses of the raw and modified samples were also performed by the FTIR-ATR method using a Nicolet 6700 spectrometer with a Specac Quest ATR diamond accessory. The morphology of the membranes and the surface modification texture were examined via scanning electron microscopy (SEM) with a Hitachi TM1000 microscope. Before testing the membrane, the samples were immersed in ethanol, placed in a liquid nitrogen bath, and broken into $1 \times 0.5 \mathrm{~mm}$ pieces. After drying, the samples were covered with a 7-10 nm gold layer using a K550X sputter coater. The gold-plated samples were tested using $300 \times$ magnification under a $15 \mathrm{kV}$ acceleration voltage. 


\subsection{Preparation of Scaffolds}

The scaffolds were made of poly-L-lactide with $\mathrm{Mn}=86,000 \mathrm{~g} / \mathrm{mol}$ Nature Works NW 2003D. The scaffolds were made by the wet and dry phase inversion methods [26]. Chloroform, ethanol, methanol, and butanol (chemically pure (AR quality) and made by POCh S.A.) were used as solvents. Solutions of $6 \%$ PLA in chloroform were obtained by dissolving the polymer for $24 \mathrm{~h}$. Membrane I (MI) was obtained by the wet method. The PLA solution was spread on the surface of the crystallizer. After that, methanol (a solvent in which the polymer was insoluble) was added to get the gelling bath. Then, phase inversion occurred (the solvent from the polymer solution diffusing into the gelling bath and the other solvent passing in the opposite direction). After removing the membrane from the gelling bath, it was dried to remove the solvents. Membrane II (MII) was obtained by the dry method. The mixture of methanol and butanol in a ratio of 1:1 was mixed with the $6 \%$ solution of PLA in chloroform. Then, this mixture was poured on a glass primer. After the formation of the membranes in the air and complete evaporation of the solvent, both membranes MI and MII were round, with a diameter of $50 \mathrm{~mm}$ and a thickness of $0.7 \mathrm{~mm}$.

The contact angles of the unmodified membranes were measured for the distilled water and diiodomethane, and they were $47.7^{\circ}$ and $24.1^{\circ}$ for $\mathrm{MI}$ and $62.7^{\circ}$ and $24.5^{\circ}$ for MII, respectively.

The SFE values of the materials before modification were $57.1 \mathrm{~mJ} / \mathrm{m}^{2}$ and $50.2 \mathrm{~mJ} / \mathrm{m}^{2}$ for MI and MII, respectively. The change in the polar component was calculated as follows:

$$
\Delta \mathrm{p}=\mathrm{pm}-\mathrm{pn}
$$

where $\mathrm{pm}$ is the polar component of the membrane after modification and pn is the polar component of the membrane before modification.

\section{Results and Discussion}

\subsection{Effect of the Discharge Power on the Surface Free Energy and Its Polar and Dispersion Components}

The effect of the discharge power generated in carbon dioxide on the polar and dispersive component and the surface free energy of the membranes MI and MII was investigated. The tests were carried out using an exposure time of $15 \mathrm{~s}$ and a discharge power of $15-50 \mathrm{~W}$.

As the discharge power increased, the surface free energy and polar component increased, and the dispersion component decreased. With a discharge power above $20 \mathrm{~W}$, the SFE and polar component decreased. At a discharge power of $20 \mathrm{~W}$, the surface free energy reached its highest values, equal to $66.1 \mathrm{~mJ} / \mathrm{m}^{2}$ and $64.2 \mathrm{~mJ} / \mathrm{m}^{2}$ for membranes MI and MII, respectively. The lowest increase of the SFE was $8 \%$ for MI and $10.5 \%$ for MII, compared with the unmodified sample. The polar component and SFE were higher for MI than MII. The plasma modification process was effective in the used discharge power range.

It was also found (Figure 3) that increasing the discharge power above $20 \mathrm{~W}$ harmed the most important membrane parameter: the polar component. $\Delta \mathrm{p}$ decreased from 12.5 to 9.4 and from 19.1 to 10.5 for MI and MII, respectively. This was probably the result of the change of the membrane's surface size and the decay of the roughness caused by melting the membrane's surface. In the rest of the studies, the discharge power was $20 \mathrm{~W}$, the exposure time varied in the range of 15-60 s, and the gas composition, in which the discharge was generated, was changed. 


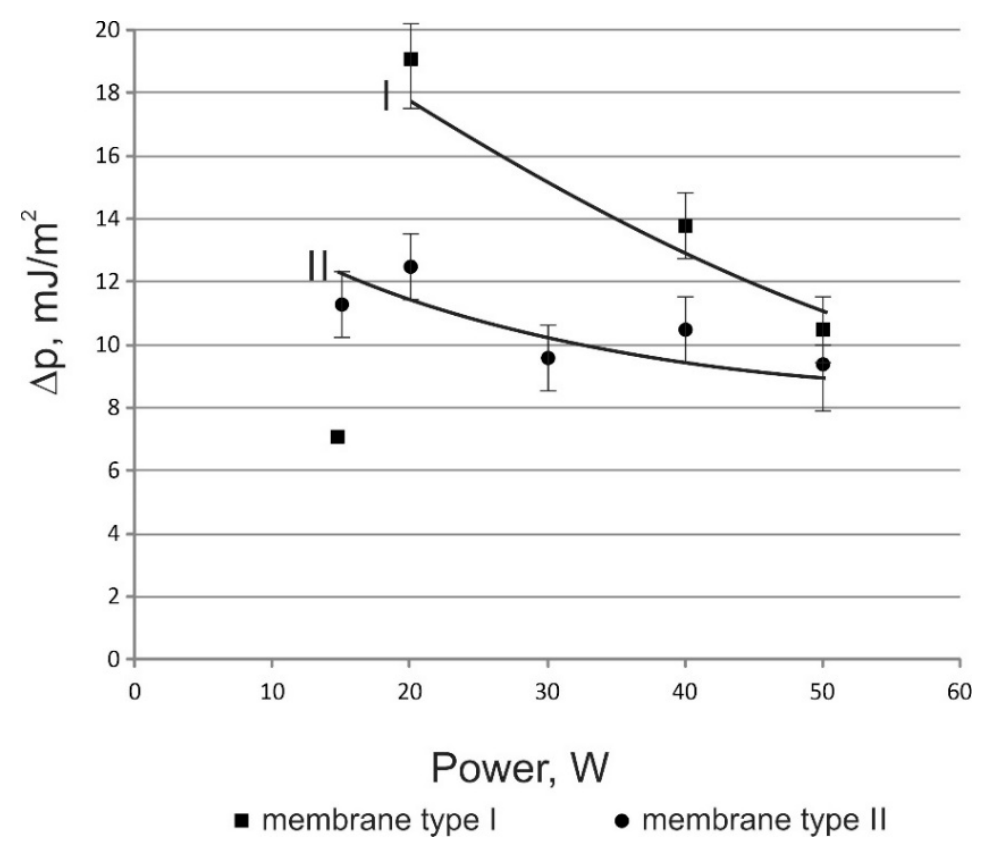

Figure 3. The impact of the barrier discharge power generated in carbon dioxide on the change of the polar component $(\Delta \mathrm{p})$. The exposure time was $15 \mathrm{~s}$.

\subsection{Effect of the Used Gas on the Surface Free Energy and Its Polar and Dispersion Components}

The effect of the gas composition on the SFE, polar and dispersion components, and the change of the polar component $(\Delta \mathrm{p})$ of membranes MI and MII was investigated. The discharge power was $20 \mathrm{~W}$, and the exposure time varied in the range of 15-60 s. It was expected that the radicals generated in the plasma by $\mathrm{CO}_{2}$ dissociation would react with the surfaces of the membranes. This may have raised the concentration of the carbonyl group on the scaffold surface. Moreover, excited argon etched the surface and may have also initiated $\mathrm{CO}_{2}$ dissociation.

It was observed that extending the modification exposure time of membranes $\mathrm{MI}$ and MII in the plasma generated in argon increased the SFE and its polar component. The modification of the MI conducted for $60 \mathrm{~s}$ allowed for a $20 \%$ increase of the value of SFE compared with the unmodified sample to be obtained, while the polar component increased from $21.4 \mathrm{~mJ} / \mathrm{m}^{2}$ to $36.3 \mathrm{~mJ} / \mathrm{m}^{2}$. A similar effect was observed for MII. The SFE of the membrane modified for $60 \mathrm{~s}$ increased by $21 \%$ compared with the unmodified sample and reached $61.0 \mathrm{~mJ} / \mathrm{m}^{2}$. The change in the polar component indicates that the introduction and formation of polar groups on the surface of the modified material improved the adhesive properties. The increase of the polar component, which was interrelated with the polar and induction effects, was a positive phenomenon. This effect will facilitate the wetting of the surface with polar liquids (e.g., water or its solutions) [27]. The dispersion component, responsible for London's interactions, decreased in value for both membranes.

The polar component of MII after the modification in argon increased almost threefold, reaching $27.8 \mathrm{~mJ} / \mathrm{m}^{2}$. The value of the dispersion component changed to a much lesser extent; it was $36.8 \mathrm{~mJ} / \mathrm{m}^{2}$ and $32.9 \mathrm{~mJ} / \mathrm{m}^{2}$ for exposure times of $15 \mathrm{~s}$ and $60 \mathrm{~s}$ (the dispersion component of the unmodified membrane was $38.6 \mathrm{~mJ} / \mathrm{m}^{2}$ ).

After the modification of MI in carbon dioxide, the best wettability was obtained after $15 \mathrm{~s}$ of exposure. The polar component value reached $34.0 \mathrm{~mJ} / \mathrm{m}^{2}$, and the surface free energy was $66.1 \mathrm{~mJ} / \mathrm{m}^{2}$. The increase of the exposure time to $30 \mathrm{~s}$ caused the decrease of the obtained values. A further extension of the exposure time to $60 \mathrm{~s}$ resulted in achieving similar SFE values to when the process was conducted for $15 \mathrm{~s}$. The differences between the values achieved at $15 \mathrm{~s}$ and $60 \mathrm{~s}$ were approximately $0.7 \%$. Similar relations were observed during the modification of MII. The most effective modification of PLA scaffolds obtained by the dry method was conducted for $15 \mathrm{~s}$. The SFE value was $64.2 \mathrm{~mJ} / \mathrm{m}^{2}$, and the polar 
component was $30.4 \mathrm{~mJ} / \mathrm{m}^{2}$, which was an almost threefold increase compared with the unmodified material.

The effects of plasma modification of membranes MI and MII conducted for $30 \mathrm{~s}$ were weak. The membranes were less flexible and more fragile, which is very unfavorable from the application point of view.

Membranes MI and MII after the treatment with DBD plasma generated in a $50 \%$ vol. $\mathrm{Ar}+50 \%_{\text {vol. }}$ air gas mixture had some of the highest SFE and polar components. All the MI samples exhibited a significant increase of the surface free energy after modification. The highest SFE value of $67.3 \mathrm{~mJ} / \mathrm{m}^{2}$ was obtained after $60 \mathrm{~s}$ of modification. The polar component obtained under these conditions was $34.4 \mathrm{~mJ} / \mathrm{m}^{2}$ and increased approximately $60 \%$ compared with the unmodified membrane. With an increasing exposure time, the SFE increased from $62.2 \mathrm{~mJ} / \mathrm{m}^{2}$ to $67.3 \mathrm{~mJ} / \mathrm{m}^{2}$, and the polar component increased from $30.6 \mathrm{~mJ} / \mathrm{m}^{2}$ to $34.4 \mathrm{~mJ} / \mathrm{m}^{2}$. Similar relations were observed for MII. It was found that the value of the SFE increased with an increasing exposure time. In the case of MII, the highest polar component and SFE values $\left(32.5 \mathrm{~mJ} / \mathrm{m}^{2}\right.$ and $60.6 \mathrm{~mJ} / \mathrm{m}^{2}$, respectively) were obtained when the membrane was modified for $60 \mathrm{~s}$. It was also found that the difference in the polar component values obtained for the exposure time in the range of 15-60 s did not exceed $1 \mathrm{~mJ} / \mathrm{m}^{2}$ (Supplementary Materials).

The most favorable membrane properties were obtained as a result of plasma treatment carried out in plasma generated in an argon and carbon dioxide gas mixture $\left(50 \%_{\mathrm{vol}} \mathrm{Ar}+\right.$ $50 \%$ vol. $\mathrm{CO}_{2}$ ). In the case of MI, the best modification effects were observed with the shortest exposure time. After $15 \mathrm{~s}$, the surface free energy was $64.3 \mathrm{~mJ} / \mathrm{m}^{2}$, and the polar component was $32.5 \mathrm{~mJ} / \mathrm{m}^{2}$. Increasing the exposure time led to lower values of the SFE and polar component.

For MII, the increase in the SFE value and the polar component was observed with an increasing exposure time. The membrane after $60 \mathrm{~s}$ of modification had a surface free energy of $67.6 \mathrm{~mJ} / \mathrm{m}^{2}$, and the polar component increased more than threefold compared with the material before modification, reaching $39.5 \mathrm{~mJ} / \mathrm{m}^{2}$. The surface free energy and polar component after modification achieved higher values for the membranes obtained by the dry method than by the wet method.

The best properties of the membranes, characterized by the highest increase of the value of the polar component $\Delta \mathrm{p}$ (which is responsible for the hydrophilic properties (Figure 4)), were obtained after the modification of MII. The highest values of $\Delta \mathrm{p}$ were obtained when the process was carried out for $60 \mathrm{~s}$ in an argon-carbon dioxide mixture. The values of the SFE and the polar component were $67.6 \mathrm{~mJ} / \mathrm{m}^{2}$ and $39.5 \mathrm{~mJ} / \mathrm{m}^{2}$, respectively, which was most likely the result of surface layer oxidation and the introduction of new functional polar groups. These values correspond to those obtained by Jordá-Vilaplana in a plasma jet in the air $\left(\mathrm{SFE}=60 \mathrm{~mJ} / \mathrm{m}^{2}\right)[16]$.

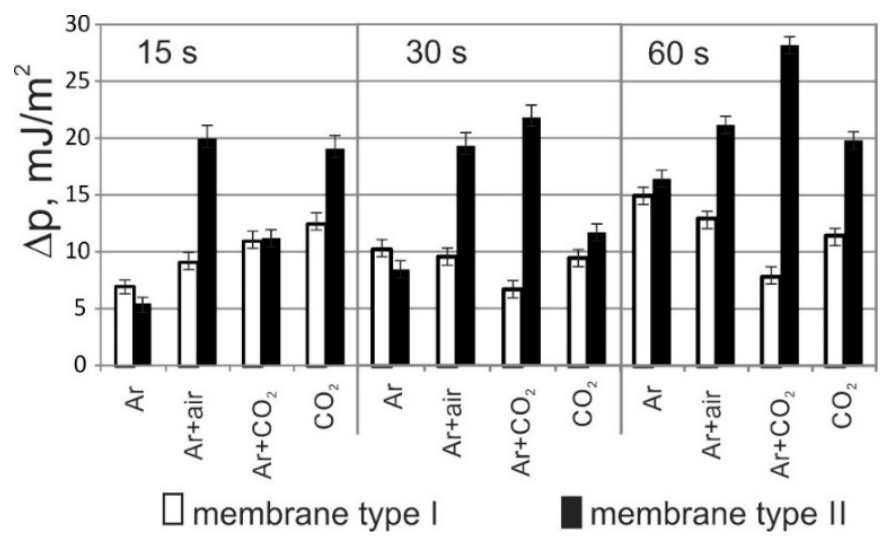

Figure 4. The effect of the used gas and exposition time on the polar component $(\Delta p)$. Discharge power $=20 \mathrm{~W}$. 


\subsection{Test of the Durability of Modification of the Surface}

The studies on the durability of the modifications were conducted for the samples with the highest surface free energy values. Two samples of MII were modified in an $\mathrm{Ar}+$ $\mathrm{CO}_{2}$ mixture with an exposure time of $60 \mathrm{~s}$ and a discharge power of $20 \mathrm{~W}$. Contact angle measurements were made immediately after modification and 30 days later (Figure 5). The sample after modification was kept in a tight string bag in air.

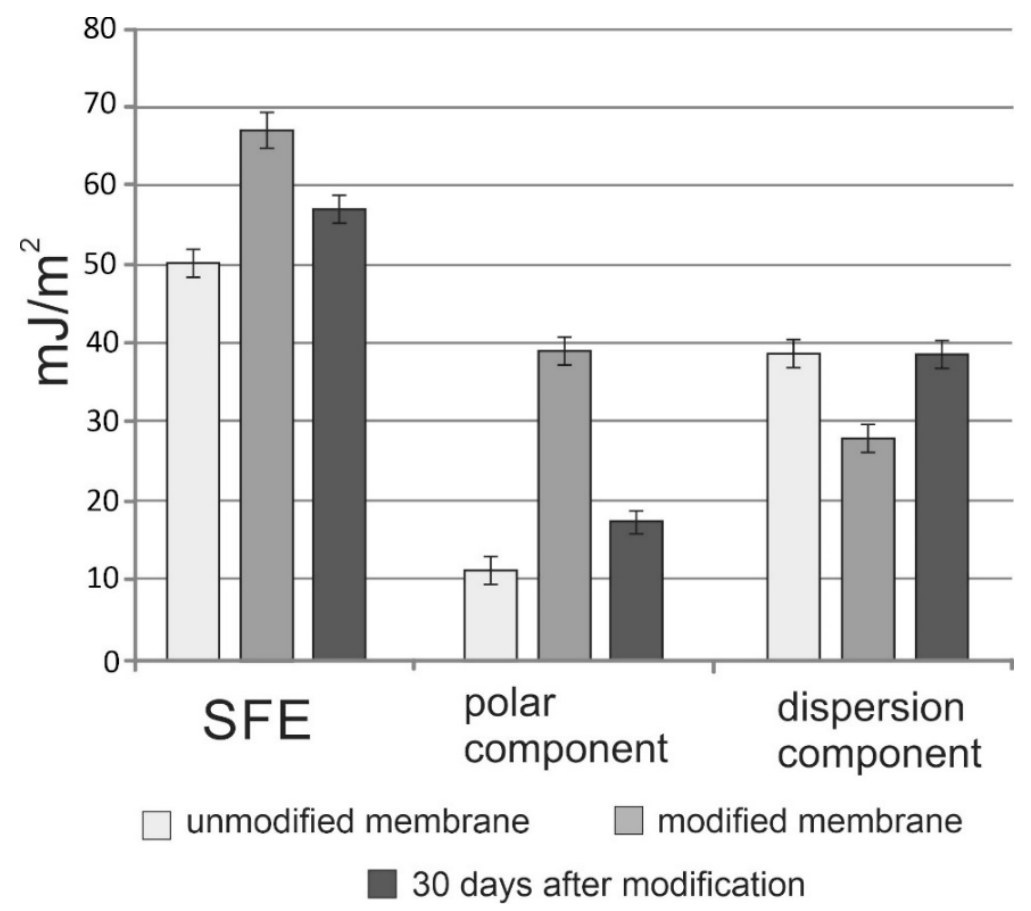

Figure 5. The results of the durability tests of plasma modification in an $\mathrm{Ar}+\mathrm{CO}_{2}$ mixture with an exposure time of $60 \mathrm{~s}$ and a discharge power of $20 \mathrm{~W}$.

The analysis of the obtained results and literature data $[15,16]$ allows us to state that the plasma modification was not a permanent process. A significant reduction of the polar component and an increase of the dispersion component to the value before modification were observed. The SFE decreased by $13 \%$ compared with the sample shortly after modification. This effect is unfavorable and could have been caused by the disappearing of polar functional groups from the surface, drawn into the volume of the material [12]. However, the polar component of the membrane after 30 days was $6.5 \mathrm{~mJ} / \mathrm{m}^{2}$ higher than that before modification.

\subsection{Analysis of the External Surface of the Membrane}

\subsubsection{Scanning Electron Microscope}

The morphologies of membranes MI and MII and the surface modification textures were examined. Surface 1 (S1) and Surface 2 (S2) formed during the preparation of the scaffold. S1 was from the glass primer side, and S2 was from the air side. The fractures on surfaces S1 and S2 were examined. The scanning area was approximately $10 \mathrm{~mm}^{2}$ for each surface and the fractures.

The SEM images (Figure 6) show the morphology of the PLA membranes obtained by wet phase inversion. S1 had small pores. Moreover, the layer observed on the surface of the unmodified membrane, which covered most of the pores and the surface itself, was very rough. After modification, most of the pores were exposed, and the surface itself appeared to be smoother. The fractures of the membrane had numerous small pores, and slight differences in the image before and after modification were observed, since two separately obtained samples were imaged. In contrast, the pores on the surface of $\mathrm{S} 2$ were much larger 
than the pores located in the deeper layers. The pores on the surface of S2 were mostly covered, so this surface could be treated as being solid. After the plasma modification, numerous large depressions were observed on S2.
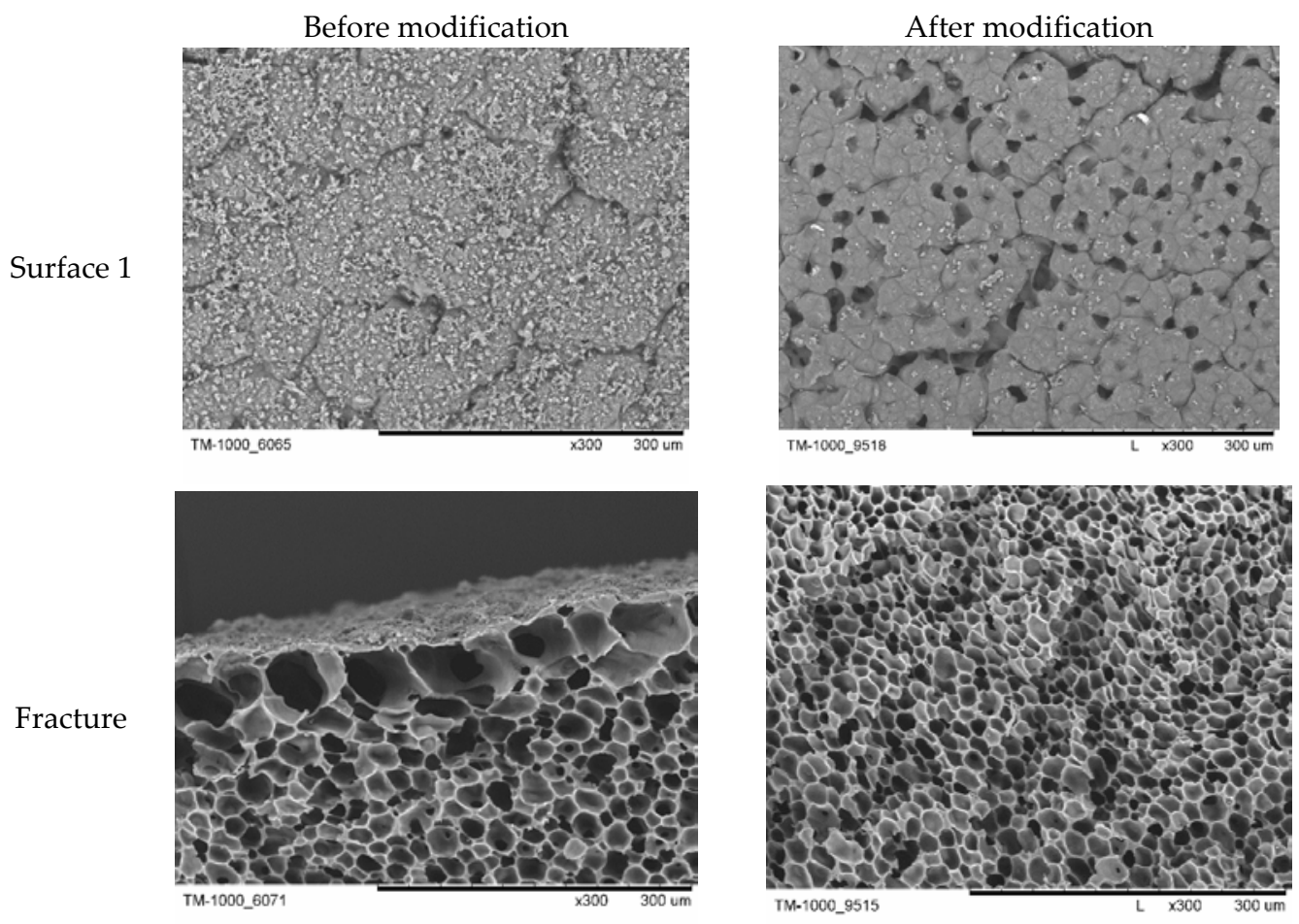

Surface 2
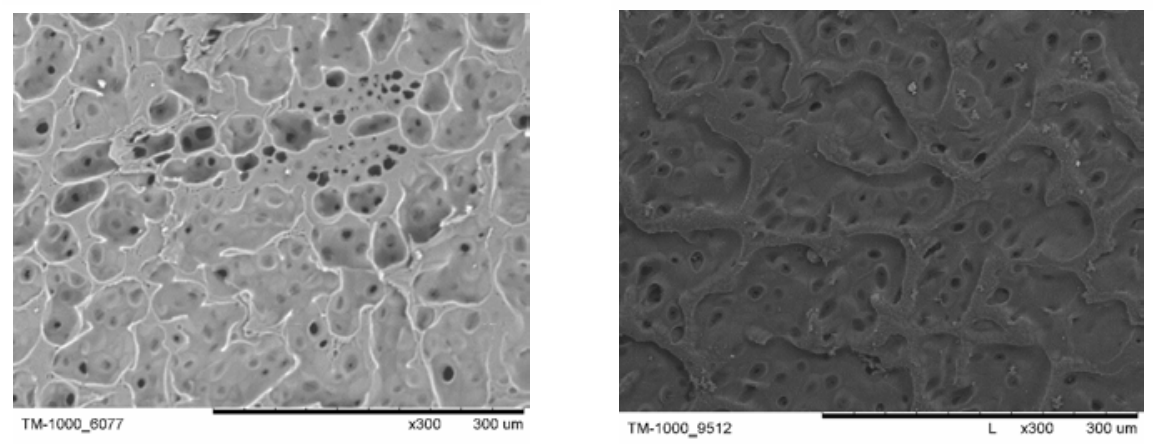

Figure 6. The morphology of Membrane I (MI) obtained before and after plasma modification.

Based on the obtained SEM images of the PLA membrane MII (Figure 7), it was found that $\mathrm{S} 1$ contained many more pores than S2. After the plasma modification, the area of the pores increased, suggesting a slight melting of the membrane surface. In the fracture of the sample, more pores were close to the membrane surface, and the surface itself has numerous large depressions. That could increase the capillary forces, reducing the water contact angle of the surface. This modification is very beneficial considering the use of the membranes for medical purposes, as it would simplify the penetration of liquid into the membrane. The fractures of the unmodified membrane and the membrane after modification looked similar, and slight differences may have been a result of the fact that they were two separate samples. S2 before and after modification was almost solid, and the use of barrier discharge plasma slightly smoothed it. 

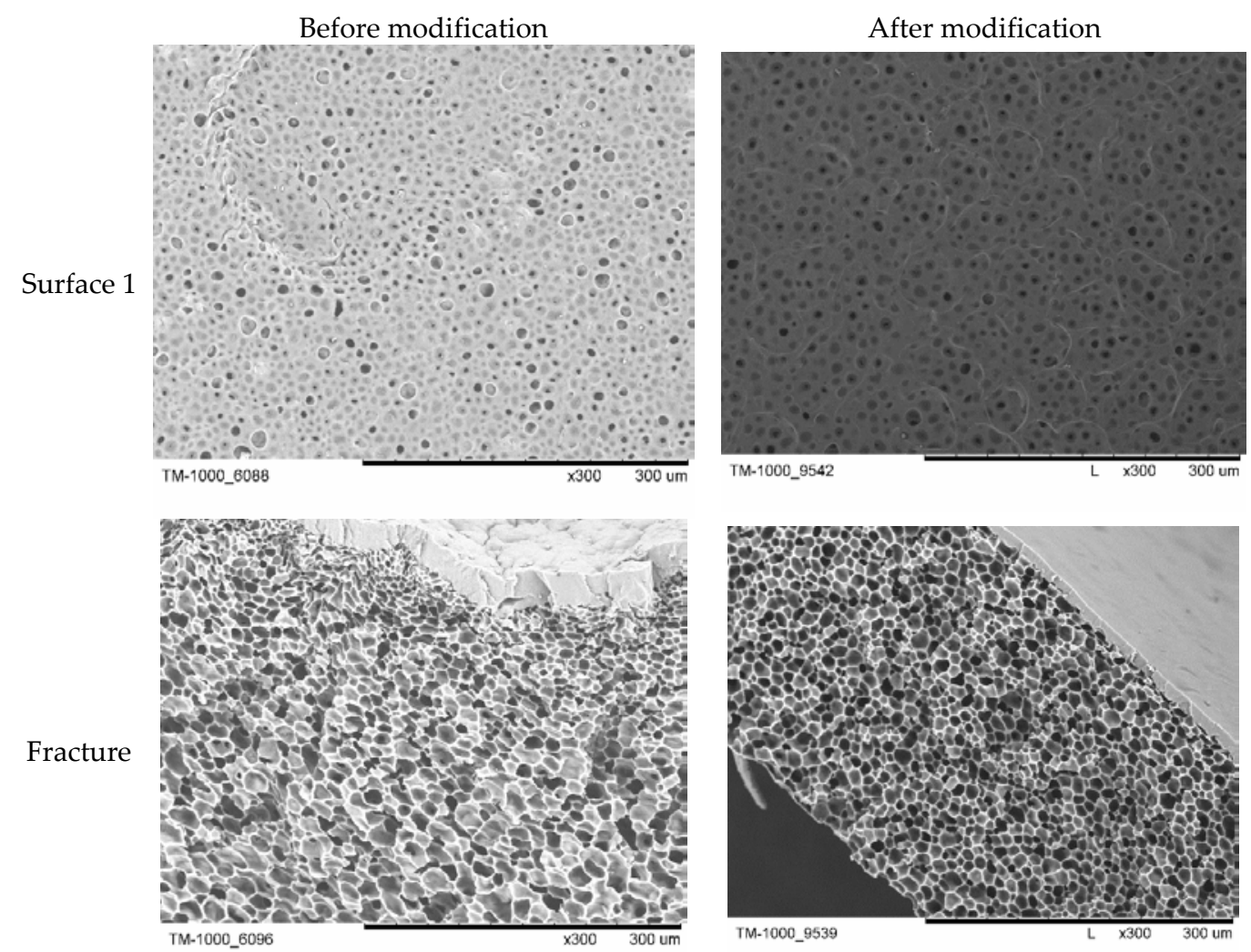

Surface 2
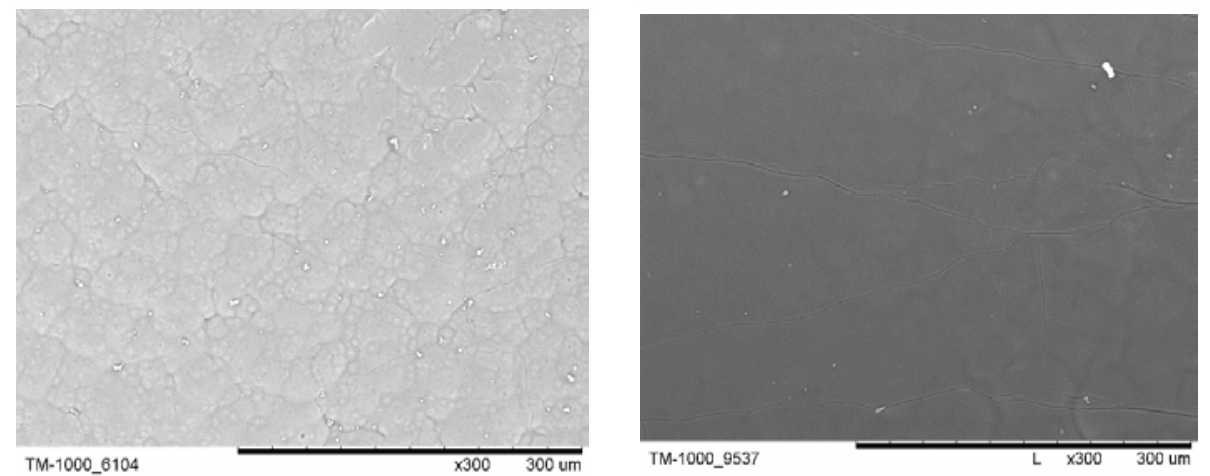

Figure 7. The morphology of Membrane II (MII) before and after plasma modification.

SEM testing of the materials after modification with DBD plasma showed that this method did not damage the pores in the membrane fractures. After the process, slight flooding of the pores on S1 was observed in the materials obtained by the wet and dry methods. The surfaces appeared less rough but contained more deep pores. Such topography can facilitate the diffusion of substances through the outer surface. During plasma modification, the pores close to S2 were slightly melted.

\subsubsection{FTIR-ATR Spectroscopy}

The unmodified samples, as well as the samples shortly after modification, were tested by FTIR-ATR analysis. Due to the high similarity of the results obtained, only an example spectrum for the tested materials was presented. On the FTIR-ATR spectra of the membrane surface after modification, no significant changes in the surface layer were observed (Figure 8). This may have been because the material undergoing the modification had oxygen-containing groups in its composition. Subsequent functional groups introduced during the process had no significant effect on the appearance of the spectra. 


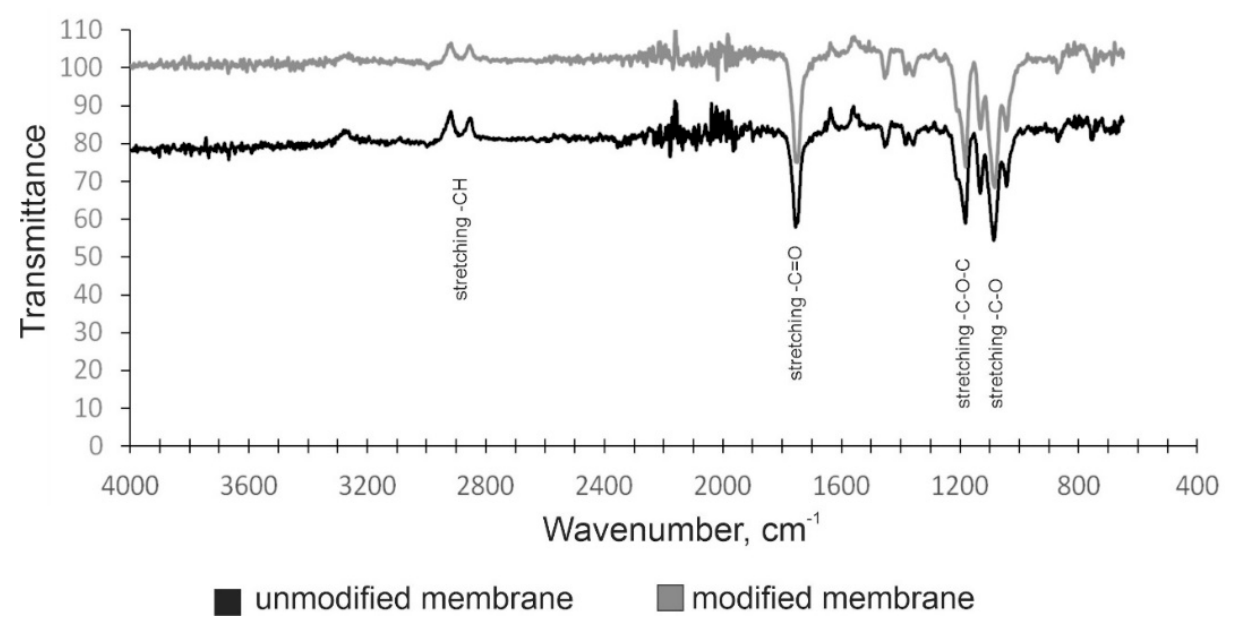

Figure 8. FTIR-ATR spectrum of the unmodified and modified samples.

The obtained results corresponded to those obtained by Hergelová, who studied the PLA surface after modification in a diffuse coplanar surface barrier discharge by FTIR spectroscopy. The results indicated that DBD plasma did not significantly affect the sample surface. Two sharp peaks were observed at a wavelength of $1748 \mathrm{~cm}^{-1}$, corresponding to $\mathrm{C}=\mathrm{O}$ stretching vibration in the group $-\mathrm{O}-\mathrm{C}=\mathrm{O}$, and another at $1181 \mathrm{~cm}^{-1}$, corresponding to -CH-O- stretching vibration. The triplet at wavelengths of 1128,1081 , and $1044 \mathrm{~cm}^{-1}$ indicates the presence of $\mathrm{C}-\mathrm{O}$ stretching vibrations in the -CO-O group. Low-intensity peaks at $2996 \mathrm{~cm}^{-1}$ and $2945 \mathrm{~cm}^{-1}$ were assigned to $\mathrm{C}-\mathrm{H}$ stretching vibrations in the $\mathrm{CH}_{3}$ group [10].

Based on the obtained results, it was found that the method using DBD plasma could be successfully used to modify the surfaces of polylactide membranes. Due to polylactide's special properties (biodegradability and biocompatibility), it is a good material for applications in tissue engineering. To conduct cell cultures on scaffolds, it is necessary to give appropriate surface properties, which can be obtained by plasma methods. Such modifications depend on many parameters (e.g., the type of gas in which the discharge was generated, the type of modified material, and the exposure time).

The best results of the modification process were obtained for MII. The increase of the SFE, compared with the unmodified material, was about $34 \%$, and the value of the polar component increased more than threefold. The material was modified in an $\mathrm{Ar}+\mathrm{CO}_{2}$ atmosphere with a discharge power of $20 \mathrm{~W}$. Very favorable results were also obtained for MII when modified in carbon dioxide and an equimolar mixture of argon and air.

For the scaffolds obtained by the dry method, it was observed that the plasma effect in an atmosphere containing $\mathrm{CO}_{2}$ was more effective than in an atmosphere with a reduced content of oxygen or inert gas. As a result of the modification in the $\mathrm{Ar}+\mathrm{CO}_{2}$ atmosphere, the contact angle of the membrane surface with water was smaller than that of the material after modification in an atmosphere of $\mathrm{CO}_{2}$ and the unmodified membrane.

The high value of the polar component indicates the formation of new polar groups on the surface of the material, which is a positive phenomenon and proves that the conducted modification process is favorable for tissue engineering. These polar groups are mainly oxygen-based species [28]. The wettability of the material increases, and its hydrophilic character increases. For most of the studied MI surfaces, a significant increase in the SFE and polar component were observed when they were modified in argon and for a $60 \mathrm{~s}$ exposure time. It was found that the obtained membranes after modification showed higher hydrophilicity and were more wettable with polar liquids; however, their porous structures were not damaged.

The highest values of the surface free energy and polar component were obtained when the process was conducted at a $20 \mathrm{~W}$ discharge power. A further increase of the discharge power did not have a positive effect on the wetting with polar liquids. Moreover, 
the material modified with a discharge power exceeding $30 \mathrm{~W}$ had a lower strength, was more fragile, and lost important mechanical properties.

\section{Conclusions}

1. The plasma of the dielectric barrier discharge influenced the surface of the polymer membranes and allowed the increase of its hydrophilicity;

2. The highest values of the SFE and polar component were obtained for a $20 \mathrm{~W}$ DBD discharge power. Exceeding this value caused the deterioration of important mechanical properties;

3. The modification was conducted in argon, carbon dioxide, and $50 \%_{\text {vol. }} \mathrm{Ar}+50 \%_{\text {vol }}$ air and $50 \%_{\text {vol. }} \mathrm{Ar}+50 \%$ vol. mixtures. $\mathrm{CO}_{2}$ caused an increase of the SFE and polar component of the membranes;

4. The obtained results indicate the high application potential of plasma polymer surface modification techniques.

Supplementary Materials: The following are available online at https:/ / www.mdpi.com/2076-341 $7 / 11 / 4 / 1815 /$ s1, Table S1. The results for the PLA membranes obtained by the wet method, Table S2. The results for the PLA membranes obtained by the dry method.

Author Contributions: Conceptualization, M.M., A.G.-G. and K.K.; Data curation, A.S.; Investigation, M.M., A.S. and A.K.; Methodology, M.M. and A.G.-G.; Writing-original draft, M.M., M.P. and K.K.; Writing-review \& editing, M.M., A.G.-G., M.P. and K.K. All authors have read and agreed to the published version of the manuscript.

Funding: This research received no external funding.

Institutional Review Board Statement: Not applicable.

Informed Consent Statement: Not applicable.

Data Availability Statement: Data is contained within the article.

Acknowledgments: This work was founded by the Warsaw University of Technology.

Conflicts of Interest: The authors declare no conflict of interest.

\section{References}

1. Balakrishnan, P.; Geethamma, V.G.; Sreekala, M.S.; Thomas, S. Fundamental Biomaterials: Polymers; Woodhead Publishing: Cambridge, UK, 2018.

2. Żenkiewicz, M.; Rytlewski, P.; Malinowski, R. Methods and devices used in modifying polymer materials with low-temperature plasma. Polimery 2011, 3, 185-195. [CrossRef]

3. Siperko, L.M.; Thomas, R. R: Chemical and physical modification of fluoropolymer surfaces for adhesion enhancement: A review. J. Adhes. Sci. Technol. 1989, 3, 157-173. [CrossRef]

4. Fabbri, P.; Messori, M. 5-Surface Modification of Polymers: Chemical, Physical, and Biological Routes. In Modification of Polymer Properties; Jasso-Gastinel, C.F., Kenny, J.M., Eds.; Elsevier Inc.: Norwich, UK, 2017; pp. 109-130.

5. Dhandayuthapani, B.; Yoshida, Y.; Maekawa, T.; Kumar, D.S. Polymeric Scaffolds in Tissue Engineering Application: A Review. Int. J. Polym. Sci. 2011, 2011, 290602. [CrossRef]

6. Amass, W.; Amass, A.; Tighe, B. A review of biodegradable polymers: Uses, current developments in the synthesis and characterization of biodegradable polyesters, blends of biodegradable polymers and recent advances in biodegradation studies. Polym. Int. 1998, 47, 89-144. [CrossRef]

7. Lendlein, A.; Sisson, A. Book Review: Handbook of Biodegradable Polymers; Wiley-VCH: Weinheim, Germany, 2014.

8. Denis, P.; Wrzecionek, M.; Gadomska-Gajadhur, A.; Sajkiewicz, P. Poly(Glycerol Sebacate)-Poly(l-Lactide) Nonwovens. Towards Attractive Electrospun Material for Tissue Engineering. Polymers 2019, 11, 2113. [CrossRef]

9. Lunt, J. Large-scale production, properties and commercial applications of polylactic acid polymers. Polym. Degrad. Stab. 1998, 59, 145-152. [CrossRef]

10. Hergelová, B. Polylactic acid surface activation by atmospheric pressure dielectric barrier discharge plasma. Open Chem. 2015, 213, 564-569. [CrossRef]

11. Jiao, Y.P.; Cui, F.Z. Surface modification of polyester biomaterials for tissue engineering. Biomed. Mater. 2007, 2, R24-R37. [CrossRef]

12. Kwiatkowski, M.; Terebun, P.; Mazurek, P.; Pawłat, J. Wettability of Polymeric Materials after Dielectric Barrier Discharge Atmospheric-pressure Plasma Jet Treatment. Sens. Mater. 2018, 30, 1207-1212. 
13. Krupa, A.; Sobczyk, A.T.; Jaworek, A. Surface Properties of Plasma-Modified Poly(vinylidene fluoride) and Poly(vinyl chloride) Nanofibres. Fibres. Text. East. Eur. 2014, 2, 35-39.

14. Kluska, S.; Pamuła, E.; Jonas, S.; Grzesik, Z. Surface Modification of Polyetheretherketon by Helium/nitrogen and Nitrous Oxide Plasma Enhanced Chemical Vapour Deposition. High Temp. Mater. Proc. 2014, 33, 147-153. [CrossRef]

15. Vergne, C.; Buchheit, O.; Eddoumy, F.; Sorrenti, E.; Di Martino, J.; Ruch, D. Modifications of the Polylactic Acid Surface Properties by DBD Plasma Treatment at Atmospheric Pressure. J. Eng. Mater. Technol. 2011, 133, 030903. [CrossRef]

16. Jordá-Vilaplana, A.; Sánchez-Nácher, L.; García-Sanoguera, D.; Carbonell, A.; Ferri, J.M. Effects of aging on adhesive properties of poly(lactic acid) (PLA) by air atmospheric plasma treatment. Appl. Polim. Sci. 2016, 133, 43040.

17. Morent, R.; De Geyter, N.; Desmet, T.; Dubruel, P.; Leys, C. Plasma surface modification of biodegradable polymers: A review. Plasma Process. Polym. 2011, 8, 171-190. [CrossRef]

18. De Geyter, N.; Morent, R. Non-Thermal Plasma Surface Modification of Biodegradable Polymers. In Biomedical Science Engineering and Technology; Ghista, D.N., Ed.; Gent University: Ghent, Belgium, 2011; pp. 225-246.

19. Fan, Y.; Li, X.; Yang, R. The Surface Modification Methods for Constructing Polymer-Coated Stents. Int. J. Polym. Sci. 2018, 3891686. [CrossRef]

20. Młotek, M.; Błaszczyk, A.; Krawczyk, K. Modification of polyethylene tube surface in dielectric barrierdischarge. J. Mater. Res. 2018, 33, 2396-2403. [CrossRef]

21. Tajima, S.; Komvopoulos, K. Effect of reactive species on surface crosslinking of plasma-treated polymers investigated by surface force microscopy. Appl. Phys. Lett. 2006, 89, 124102. [CrossRef]

22. Dryakhlov, V.O.; Shaikhiev, I.G.; Galikhanov, M.F.; Sverguzova, S.V. Modification of Polymeric Membranes by Corona Discharge. Membr. Membr. Technol. 2020, 2, 195-202. [CrossRef]

23. Popelka, A.; Khanam PN, M.; AlMaadeed, A. Surface modification of polyethylene/graphene composite using corona discharge. J. Phys. D Appl. Phys. 2018, 51, 105302. [CrossRef]

24. Młotek, M.; Zalewska, M.; Szafran, M.; Krawczyk, K. Reactor for Modification of Porous Polymers. Polish Patent $234557,2020$.

25. Kruk, A.; Gadomska-Gajadhur, A.; Rykaczewska, I.; Ruśkowski, P.; Dulnik, J.; Synoradzki, L. Influence of liquid pore precursors on morphology and mechanical properties of cells scaffolds obtained by dry inversion phase method. J. Biomed. Mater. Res. B 2019, 107, 1079-1087. [CrossRef] [PubMed]

26. Kruk, A.; Gadomska-Gajadhur, A.; Dulnik, J.; Ruśkowski, P. The influence of the molecular weight of polymer on the morphology, functional properties and L929 fibroblasts growth on polylactide membranes for tissue engineering. Int. J. Polym. Mater. Polym. Biomater. 2020. [CrossRef]

27. Żenkiewicz, M. Adhesion and Modification of the Surface Layer of Macromolecular Materials; WNT: Warsaw, Poland, 2000.

28. Jordá-Vilaplana, A.; Fombuena, V.; García-García, D.; Samper, M.D.; Sánchez-Nácher, L. Surface modification of polylactic acid (PLA) by air atmospheric plasma treatment. Eur. Polym. J. 2014, 58, 23-33. [CrossRef] 